\title{
Estimation of Measurement Uncertainties for the DGT Passive Sampler Used for Determination of Copper in Water
}

\author{
Jesper Knutsson, Sebastien Rauch, and Gregory M. Morrison \\ Department of Water Environment Technology, Division of Civil and Environmental Engineering, \\ Chalmers University of Technology, 41296 Göteborg, Sweden \\ Correspondence should be addressed to Jesper Knutsson; jesper.knutsson@chalmers.se
}

Received 20 May 2014; Accepted 24 July 2014; Published 1 September 2014

Academic Editor: Mohammad R. Pourjavid

Copyright (C) 2014 Jesper Knutsson et al. This is an open access article distributed under the Creative Commons Attribution License, which permits unrestricted use, distribution, and reproduction in any medium, provided the original work is properly cited.

\begin{abstract}
Diffusion-based passive samplers are increasingly used for water quality monitoring. While the overall method robustness and reproducibility for passive samplers in water are widely reported, there has been a lack of a detailed description of uncertainty sources. In this paper an uncertainty budget for the determination of fully labile $\mathrm{Cu}$ in water using a DGT passive sampler is presented. Uncertainty from the estimation of effective cross-sectional diffusion area and the instrumental determination of accumulated mass of analyte are the most significant sources of uncertainty, while uncertainties from contamination and the estimation of diffusion coefficient are negligible. The results presented highlight issues with passive samplers which are important to address if overall method uncertainty is to be reduced and effective strategies to reduce overall method uncertainty are presented.
\end{abstract}

\section{Introduction}

The overall goal of environmental management programs is to provide a framework for assessing environmental status, identifying problem areas, and to continuously assess quality indicators to ensure that those are within established acceptable limits which ensure a "good and nondeteriorating status." One of the indicators of environmental quality outlined by the Water Framework Directive of the European Union is heavy metal concentration in water bodies, including $\mathrm{Cu}, \mathrm{Pb}$, $\mathrm{Cd}$, and $\mathrm{Ni}[1]$. There is therefore a stated need to measure and assess the environmental concentration of these metals. This should be done using a method that is representative and that provides comparable results across EU member states, though the directive does not specify what level of uncertainty is considered sufficient.

A passive sampler is a device used to collect a target analyte in situ, both in gaseous and liquid media. Recently, passive samplers have found increasing use in the determination of metals and organic contaminants in water [2-4]. However, measurement uncertainty, relatively little investigated, is a perceived limitation of passive sampling in comparison to the more conventional grab and automated bottle sampling procedures. The work presented here aims at characterizing and assessing the uncertainty associated with the determination of time-weighted concentrations of labile metal ions in freshwater using passive sampling.

A passive sampler for metal sampling is typically composed of a membrane filter, a diffusion layer gel, and a receiving phase placed in a sampler housing, like the DGT (diffusive gradients in thin films) technique (Figure 1). The DGT passive sampler was first described by Allan et al. [4] and since then the technique has been used in a wide range of applications and is one the most widely used passive sampler techniques for quantification and speciation of metals in aquatic environments. The analyte accumulates on the receiving phase as a result of the chemical affinity of the analyte for the solid receiving phase. The amount of analyte accumulated is proportional to the average concentration of labile analyte in the water, the time the sampler is exposed, and other aquatic environmental factors such as temperature and turbulence. After sampler retrieval and determination of the collected amount of metal, the average bulk concentration of metal can be calculated (see [3-5])

$$
c_{b}=\frac{\left(M_{\mathrm{acc}}-M_{\text {blank }}\right)\left(D^{w} \Delta g+D^{\mathrm{MDL}} \delta\right)}{t D^{w} D^{\mathrm{MDL}} A_{e}} .
$$

See [6]. 


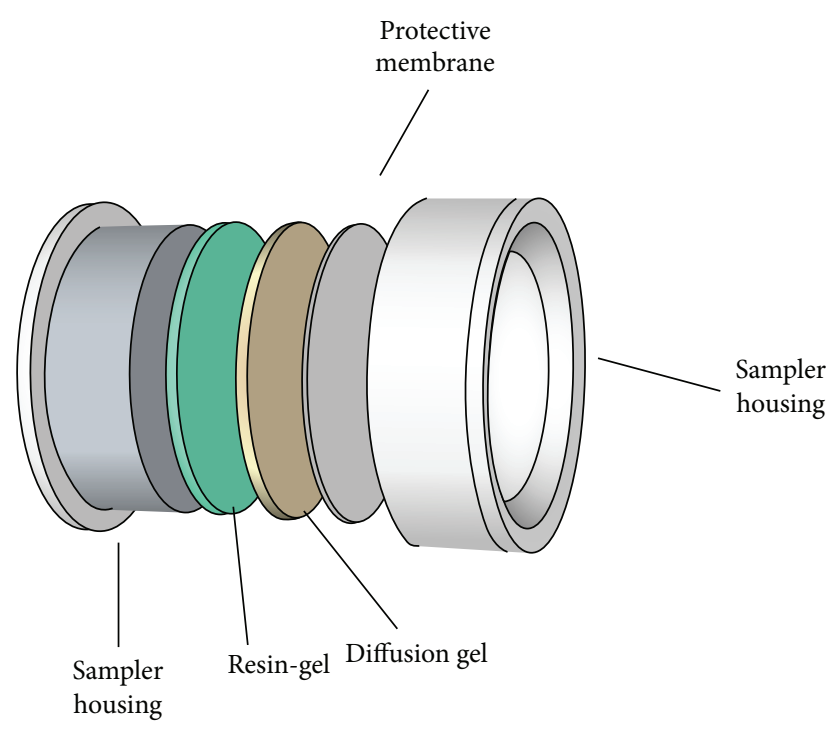

FIGURE 1: A schematic render of a DGT passive sampler showing its principal components.

In (1), $c_{b}$ denotes the bulk concentration of the analyte in the water body, $M_{\text {acc }}$ is the mass of the analyte accumulated on the sampler, $D^{W}$ is the diffusion coefficient of the analyte in water at $20^{\circ} \mathrm{C}, \Delta g$ is the thickness of material diffusion layer (MDL, consisting of membrane filter and diffusion layer gel), $D^{\mathrm{MDL}}$ is the diffusion coefficient of the analyte in the MDL, $\delta$ is the effective thickness of the diffusion boundary layer that is formed at the water-sampler interface, $t$ is the time of exposure, and $A_{e}$ is the effective sectional area of diffusion.

Although there has been some consideration of overall uncertainty in passive sampler measurements [7], there is no published study evaluating the components of this uncertainty. The identification of key components contributing to overall uncertainty can support the improvement of procedures based on passive samplings, as well as reducing potential concerns about performance and reliability [7].

\section{Materials and Methods}

For the purpose of this study, a simple case was assumed; a DGT passive sampler with characteristics listed in Table 1 was used to determine dissolved $\mathrm{Cu}$ concentration in water $\left(c_{b}=1.28 \pm 0.16 \times 10^{-6} \mathrm{gl}^{-1}\right)$. We note that the estimation of uncertainty resulting from metal-ligand interactions is out of the scope of this paper and $\mathrm{Cu}$ is therefore considered fully labile and present as $\mathrm{Cu}^{2+}$. In the absence of metal complexes, the time weighted average concentration can be derived using (1).

The uncertainty budget presented here was estimated for a generic passive sampler under predefined environmental conditions (Table 1). The characteristics of the passive samplers were chosen based on the characteristics of existing commercially available samplers (DGT Research Ltd.) and the availability of data. Similarly, environmental conditions were selected based on the availability of data for specific samplers. Although a number of passive sampler technologies have been described in the literature [8-11], the general methodology presented in this work should be applicable to estimate measurement uncertainty for a broad range of passive samplers, even if the specific conclusions for the passive sampler system assessed here does not necessarily hold true for other types.

Uncertainty in passive sampling is expected from all steps in the analytical process, including preparation of the samplers, deployment, analyte extraction, analysis, and estimation of diffusion rates and pathways. Overall, the estimation of uncertainties and the propagation of uncertainties were based on standard methodology [12]. Input data for the calculation were obtained from the literature and our own results, depending on availability. A cause and effect diagram was created to visualize the sources of uncertainty in the analytical chain when using a passive sampler to determine time weighted average bulk concentration (Figure 2). A list of relevant parameters (see Table 2) was identified from the cause and effect diagram and the model equation as a basis for the construction of the uncertainty budget.

\section{Results and Discussion}

\subsection{Uncertainties in Analyte Accumulation}

3.1.1. Diffusional Pathway. When deploying a prepared passive sampler, the fully labile metal ion $\left(\mathrm{Cu}^{2+}\right)$ accumulates on the receiving phase and the accumulation rate is governed by diffusion across a diffusion boundary layer (DBL, see Figure 3), a membrane filter of known thickness $(0.135 \mathrm{~mm})$, and a gel layer of a known thickness $(0.80 \mathrm{~mm})$. No assessment was found of the uncertainty of $\Delta g$, but a low uncertainty level was assumed for the combined membrane filter and gel layer $(0.935 \pm 0.05 \mathrm{~mm})$ based on the authors judgement [12].

The DBL is the water layer closest to the passive samplerwater interface that is not affected by the mixing conditions in the bulk water phase. This measure is a representation of the effective DBL as this is neither evenly distributed layer across the surface nor a true unmixed layer but rather a velocity gradient. The effective thickness of the DBL is subject to uncertainty. The uncertainty can be reduced by deploying several devices with varying $\Delta g$, as described by Zhang et al. [13], but this procedure increases the scope and cost of measurement considerably. Therefore in the hypothetical scenario presented here, the DBL thickness was estimated to be $0.26 \pm 0.05 \mathrm{~mm}$, covering a wide range of flow regimes, from fast flowing water to slow moving lake epilimnion [6]. The diffusion coefficient of the metal ion $\mathrm{Me}^{2+}$ depends in turn on the water temperature and on which media it is diffusing in. The total accumulated amount $(M)$ depends on the accumulation rate and the length of the exposure in time $(t)$.

3.1.2. Diffusion Coefficients. The diffusion coefficients $D^{W}$ and $D^{\mathrm{MDL}}$ are usually determined experimentally in a separate experiment. The determination itself is associated with 


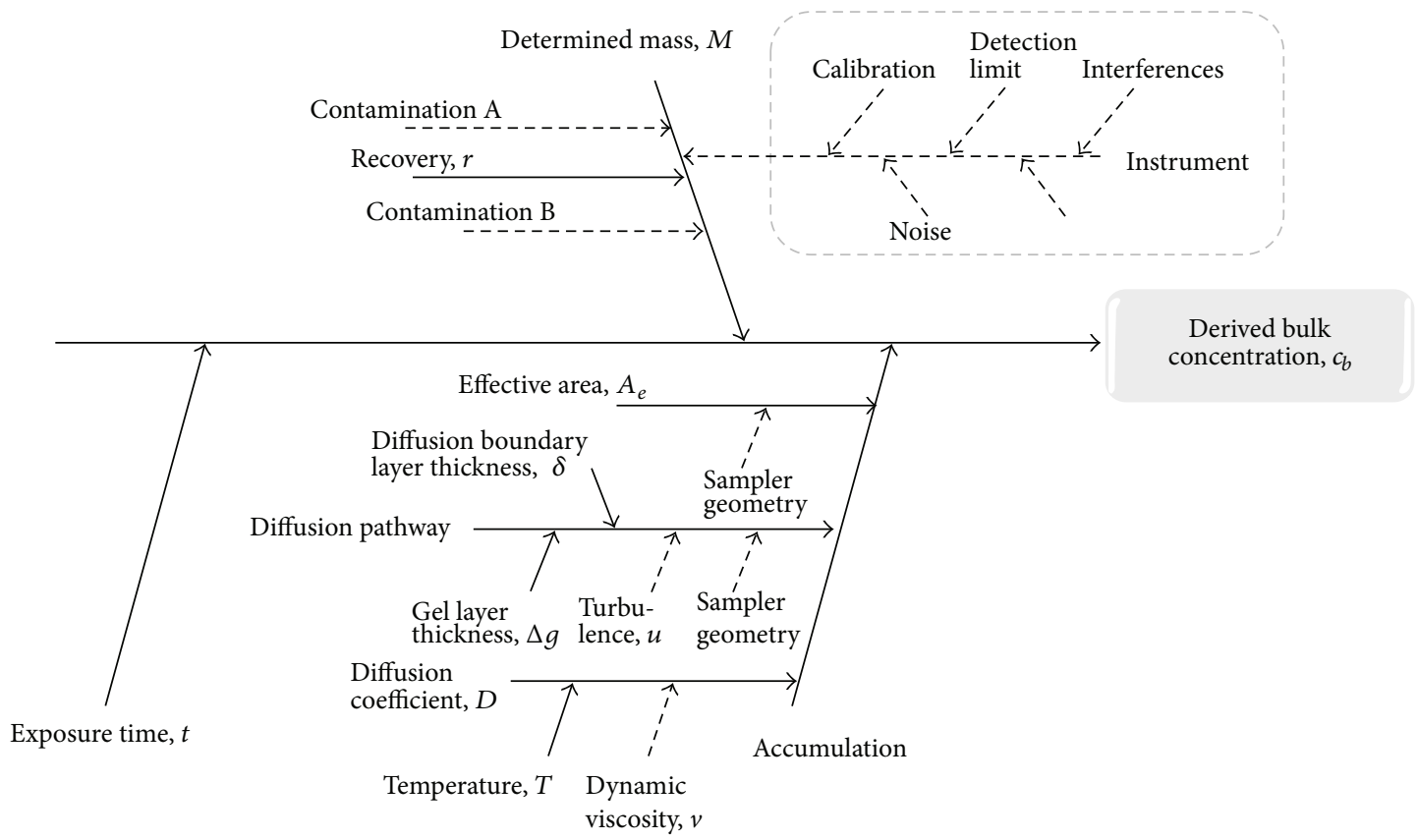

FIGURE 2: Cause and effect diagram describing the uncertainties associated with the determination of bulk concentration $c_{b}$, using a passive sampler. Dashed arrows indicates parameters whose uncertainty contribution was included in another parameter. The dashed box shows the uncertainty from instrument determination of analyte. Uncertainty analysis of the ICP-MS technique has been performed previously [19,22] and was therefore not treated separately in this paper.

TABLE 1: Predefined passive sampler characteristics and environmental conditions used as a basis in the uncertainty calculations.

\begin{tabular}{lc}
\hline Parameter & Property/Value \\
\hline Passive sampler & $2 \mathrm{~cm}$ \\
Diameter & Acrylamide gel with APA cross-linker (APA2) [23] \\
Diffusion layer & $135 \mu$ m thickness and $0.45 \mu \mathrm{m}$ pore size \\
Cellulose nitrate membrane & Resin-gel containing Chelex resin \\
Receiving phase & 7.5 \\
Environmental conditions & $25^{\circ} \mathrm{C} / 298 \mathrm{~K}$ \\
pH & Estimated \\
Water temperature & \\
Turbulence & \\
\hline
\end{tabular}

TABLE 2: Parameters for which uncertainty is determined and respective units.

\begin{tabular}{lcc}
\hline Parameter & Unit & Definition \\
\hline$A_{e}$ & $\mathrm{~m}^{2}$ & Effective area of diffusional cross-section \\
$D^{\mathrm{MDL}}$ & $\mathrm{m}^{2} \mathrm{~s}^{-1}$ & $\mathrm{Diffusion} \mathrm{coefficient} \mathrm{of} \mathrm{the} \mathrm{Cu}^{2+}$ ion in the $\mathrm{MDL}$ \\
$D^{W}$ & $\mathrm{~m}^{2} \mathrm{~s}^{-1}$ & Diffusion coefficient of the $\mathrm{Cu}^{2+}$ ion in water \\
$M$ & $\mathrm{~g}$ & Accumulated amount of $\mathrm{Cu}^{2+}$ determined from sample \\
$M_{\text {blank }}$ & $\mathrm{g}$ & Contamination determined from field blank \\
$r$ & $\mathrm{~K}$ & Recovery during the extraction phase \\
$T$ & hours & Temperature in bulk water phase \\
$t$ & $\mathrm{~m}$ & Exposure time \\
$\delta$ & $\mathrm{m}$ & Diffusional boundary layer thickness \\
$\Delta g$ & & Diffusional pathway thickness of the MDL \\
\hline
\end{tabular}




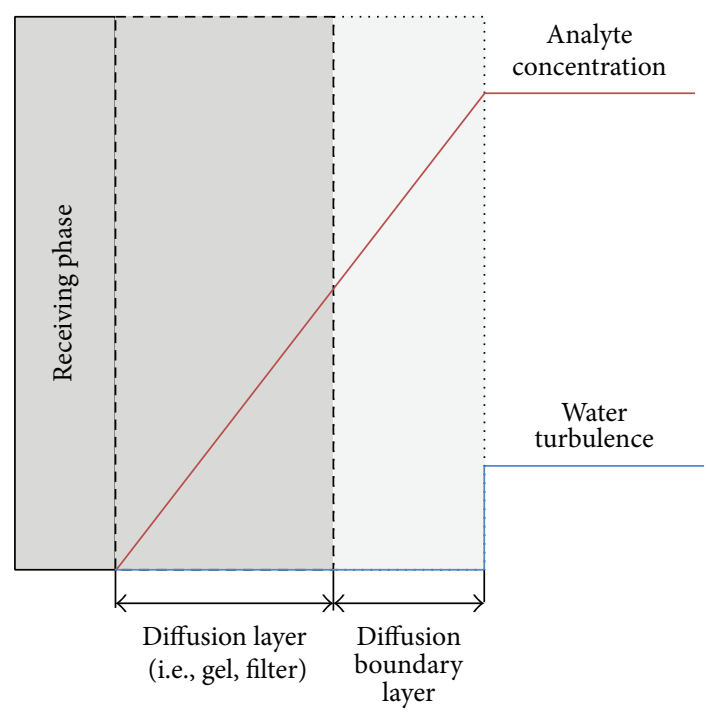

FIGURE 3: Schematic representation of the concentration gradient that forms over the diffusional pathway.

uncertainty, and results are typically reported without associated uncertainty. A typical relative uncertainty of diffusion coefficients has been reported in the range $1.3-6.4 \%[14,15]$ and for the purpose of this assessment we will use a $D^{\mathrm{MDL}}$ value of $6.42 \times 10^{-10} \mathrm{~m}^{2} \mathrm{~s}^{-1}$, which is the diffusion coefficient of $\mathrm{Cu}^{2+}$ in APA2 gel (a polyacrylamide hydrogel containing $15 \%$ vol acrylamide and $0.3 \%$ agarose-derived cross-linker) and the upper value in the uncertainty interval, that is, 6.4\% [15]. The diffusion coefficient of $\mathrm{Cu}^{2+}$ in water $\left(D^{W}\right)$ is reported to be 1.14 times larger at $7.30 \times 10^{-10} \mathrm{~m}^{2} \mathrm{~s}^{-1}$ [15]. For the purpose of this paper that same relative uncertainty was applied to both $D^{\mathrm{MDL}}$ and $D^{W}$. It should be noted that effective diffusion coefficients may also be significantly affected in low ionic strength solutions $(<1 \mathrm{mM})$.

The diffusion coefficient $D$ depends on water temperature as described by the Stokes-Einstein equation:

$$
D=\frac{k_{b} T}{3 \pi \mu d}
$$

where $k_{b}$ is the Boltzmann constant $\left(\mathrm{m}^{2} \mathrm{~kg} \mathrm{~s}^{-2} \mathrm{~K}^{-1}\right), T$ is the temperature $(\mathrm{K}), \mu$ is the viscosity of the medium $\left(\mathrm{kg} \mathrm{s}^{-1} \mathrm{~m}^{-1}\right)$, and $d$ is the spherical diameter of the diffusing particle.

The uncertainty introduced from variability of $T$ was analysed $(D(T))$. The uncertainty in the experimental determination of $D$ was also estimated. The standard uncertainty in $D^{W}$ from uncertainty in water temperature was calculated to be $0.06 \times 10^{-10} \mathrm{~m}^{2} \mathrm{~s}^{-1}$, and the combined standard uncertainty from the determination of $D^{W}$ and temperature was calculated through summation in quadrature to be $7.30 \pm$ $0.47 \times 10^{-10} \mathrm{~m}^{2} \mathrm{~s}^{-1}$. A similar treatment of $D^{\mathrm{MDL}}$ resulted in $6.42 \pm 0.10 \times 10^{-10} \mathrm{~m}^{2} \mathrm{~s}^{-1}$.

3.1.3. Effective Area. The effective area of the section through which diffusion occurs has been reported to be somehow larger than the nominal area due to lateral diffusion; that is, diffusion occurs in three dimensions [6,7]. Warnken et al. report that the radius of the effective diffusion window is $1.02 \pm 0.024 \mathrm{~cm}$ and also note that the gel disc diameter had shrunk on average $0.12 \mathrm{~cm}(n=6)$ during drying prior to determination of the radius [16]. No estimate on uncertainty was given for this measure, so a $0.05 \mathrm{~cm}$ uncertainty was assumed based on the number of significant figures reported, and a rectangular distribution was selected due to the lack of information on the measurement.

Summation in quadrature was used to combine the uncertainties from the determination of effective radius and the estimation of the shrinkage in order to calculate the total uncertainty associated with the effective area [17]. The divisor $\sqrt{3}$ was used to get the standard uncertainty of the shrinkage because of the assumed rectangular distribution, followed by summation in quadrature:

$$
U_{c}=\sqrt{u_{i}\left(r_{\text {disc }}\right)^{2}+\left(\frac{u_{i}\left(r_{\text {shrinkage }}\right)}{\sqrt{3}}\right)^{2}} .
$$

The combined uncertainty of the effective radius was calculated to be $0.0449 \mathrm{~cm}$, making the effective radius of the sampler $1.08 \pm 0.04 \mathrm{~cm}$. Using the derivative of the circle area function to calculate the uncertainty of the effective area, $A_{e}$, gave the value $3.66 \pm 0.30 \mathrm{~cm}^{2}$.

\subsection{Uncertainties in Determination of Mass}

3.2.1. Preparation and Handling. During preparation, transport, storage, and handling of the passive sampler devices there is a risk of contamination. The best assessment of the uncertainty from these sources comes from the use of field blanks [18]. The field blanks can be used to correct for contamination issues. We have estimated during field trials that the associated relative uncertainty resulting from contamination is typically in the order of $24 \%$ for passive sampler devices, with field blank values of $8.1 \pm 2.0 \mathrm{ng} \mathrm{Cu}^{2+}$ $(n=3)$ (unpublished data).

3.2.2. Extraction. The analyte $\left(\mathrm{Cu}^{2+}\right)$ is subsequently extracted from the receiving phase using a small volume of nitric acid. The recovery factor, $r$, has been reported previously $(0.793 \pm 0.051)$ [5]. The uncertainty was reported as an interval, and therefore a rectangular distribution was assumed.

3.2.3. Analysis/Determination. The resulting extract is diluted to a suitable volume concentration before analysis by a selected analytical technique. Inductively coupled plasma-mass spectrometry (ICP-MS) is widely used for the determination of trace metal concentrations in environmental samples and therefore, we estimate uncertainty for ICP-MS analysis in this paper. The ICP-MS instrument is calibrated using calibration standards prepared from certified standard solutions.

Generally, the analytical procedure using ICP-MS is subject to known and unknown interferences of which some 


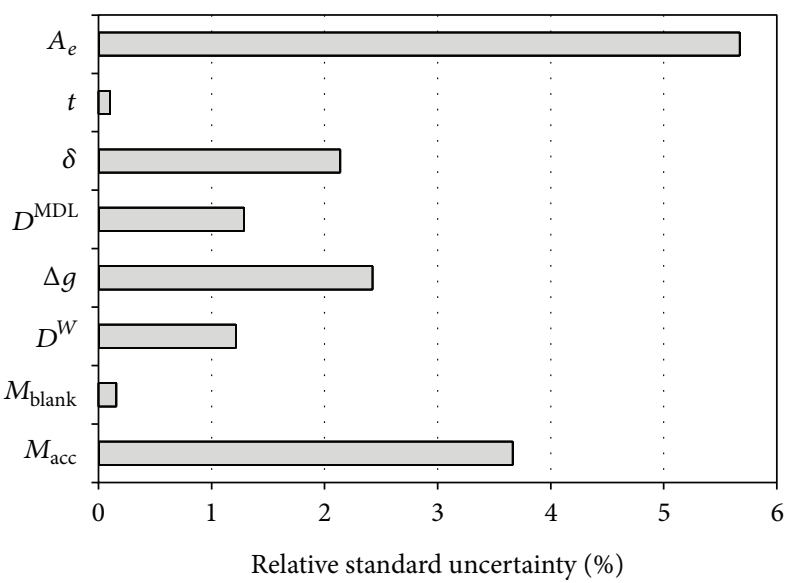

(a)

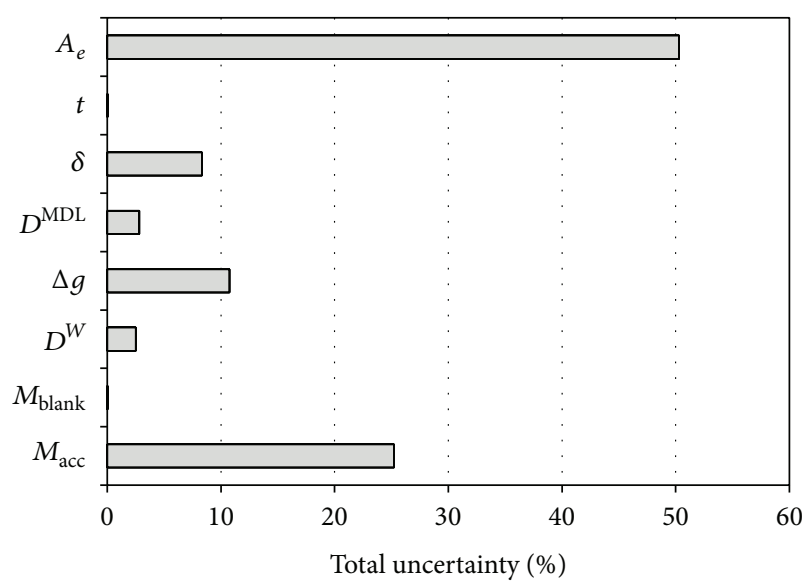

(b)

FIGURE 4: Relative standard uncertainty (a) and percentage of total uncertainty (b) for the variables in the model equation.

TABLE 3: Uncertainty budget for $M_{\text {acc }}$ showing relative uncertainties for the variables and the combined standard uncertainty.

\begin{tabular}{lcccccc}
\hline Symbol & Source of uncertainty & Type $^{*}$ & Standard uncertainty $u\left(x_{i}\right)$ & Distribution & Divisor & Relative uncertainty \\
\hline$m_{\text {icp-ms }}$ & Estimated mass from ICP-MS analysis & $\mathrm{A}$ & $1.0 \times 10^{-8} \mathrm{~g}$ & Normal & 1 & 0.008 \\
$r$ & Recovery factor & $\mathrm{B}$ & 0.0293 & Rectangular & $\sqrt{3}$ & 0.064 \\
$\mathrm{Uc}(\mathrm{M})$ & Combined standard uncertainty & $\mathrm{A}$ & $6.15 \times 10^{-8} \mathrm{~g}$ & Normal & 0.038 \\
\hline
\end{tabular}

* Note: type of uncertainty refers to types A and B, using standard vocabulary for statistically evaluated uncertainty (A) and uncertainty evaluated by other methods (B).

can be compensated for, while others may persist, depending on specific instrument capabilities [18]. Furthermore, instrument drift, stability of stock solutions, and density of stock solutions will contribute to uncertainty [18] and the uncertainty budget of the instrumental analysis is a comprehensive topic in its own right. A simplified view is given in Figure 2 to highlight the importance of the analytical step. However, instrument performance and the typical uncertainty of the method have been addressed elsewhere [19] and are not repeated here. The reported standard relative uncertainty for $\mathrm{Ni}$ solutions containing $10 \mathrm{ng} \mathrm{g}^{-1}$ or more was $7.5 \%$, which was used for the calculations in this paper.

The estimated accumulated mass and mass on blank samples was determined using ICP-MS and then corrected for by the recovery factor according to

$$
M_{\mathrm{acc} / \mathrm{blank}}=\frac{m_{\mathrm{icp}-\mathrm{ms}}}{r} .
$$

Using the rule for uncertainty propagation in quotients the estimate for $M_{\mathrm{acc}}$ becomes $1.63 \pm 0.06 \times 10^{-6} \mathrm{~g}$ (see Table 3). A similar treatment of $M_{\text {blank }}$ resulted in $0.010 \pm$ $0.003 \times 10^{-6} \mathrm{~g}$.

\subsection{Total Combined Uncertainty of the Passive Sampler Mea-} surement. To estimate the combined standard uncertainty of the bulk concentration $c_{b}$, the relation in the model equation (1) was used. Since it was a mixed expression, the rule of uncertainty propagation states that the combined uncertainty can be calculated using

$$
\partial Q=\sqrt{\left(\frac{\partial q}{\partial x} \delta x\right)^{2}+\cdots+\left(\frac{\partial q}{\partial z} \delta z\right)^{2}}
$$

See [20].

This means that the combined uncertainty is equal to the root square sum of the partial derivatives of the variables. However, it is also possible to derive a numerical solution as suggested by Kragten [21]. The approximation derived from this numerical method assumes linearity and small values of relative uncertainty, $u\left(x_{i}\right) / x_{i}$. While this is not always the case, the accuracy of the solution is still acceptable for most practical purposes [21].

A summary of the quantities and the associated standard uncertainties is presented in Table 4.

During calculations values were not rounded to avoid the introduction of additional uncertainty. The output of the numerical treatment of combined uncertainties can be seen in Table 5. The measurement output with associated uncertainty was $c_{b}=1.32 \pm 0.100 \mu \mathrm{gl}^{-1}$. Using a coverage factor $k=2$ the result was instead $1.32 \pm 0.200 \mu \mathrm{gl}^{-1}$ (confidence interval $\approx 95 \%$ ), or a relative uncertainty of $7.6 \%$ at $k=1$.

When plotting the relative standard uncertainties of the components graphically (Figure 4) it is obvious that the largest uncertainty was introduced from the effective cross-sectional area estimate $\left(A_{e}\right)$. The combined estimated uncertainties resulting from the determination of the lateral 
TABLE 4: Quantities, nominal values, and their associated uncertainty used in this work.

\begin{tabular}{lccc}
\hline Quantity & Value & Standard uncertainty & Comment \\
\hline$A$ & $3.66 \mathrm{~cm}^{2}$ & $0.30 \mathrm{~cm}^{2}$ & See previous section and [16] \\
$D^{\mathrm{MDL}}$ & $6.42 \times 10^{-10} \mathrm{~m}^{2} / \mathrm{s}$ & $0.09 \times 10^{-10} \mathrm{~m}^{2} / \mathrm{s}$ & Empirical value [15] \\
$D^{W}$ & $7.30 \times 10^{-10} \mathrm{~m}^{2} / \mathrm{s}$ & $0.47 \times 10^{-10} \mathrm{~m}^{2} / \mathrm{s}$ & Empirical value [15] \\
$M_{\text {acc }}$ & $1.29 \times 10^{-6} \mathrm{~g}$ & $0.01 \times 10^{-6} \mathrm{~g}$ & Observation \\
$M_{\text {blank }}$ & $0.008 \times 10^{-6} \mathrm{~g}$ & $0.002 \times 10^{-6} \mathrm{~g}$ & Observation \\
$r$ & 0.793 & 0.051 & Observation [5] \\
$t$ & $168 \mathrm{~h}$ & $0.3 \mathrm{~h}$ & Covers the time it takes to deploy and retrieves 5 passive samplers \\
$T$ & $25^{\circ} \mathrm{C} / 298 \mathrm{~K}$ & $4 \mathrm{~K}$ & Standard deviation of the measured temperature \\
$\delta$ & $0.26 \times 10^{-3} \mathrm{~m}$ & $0.05 \times 10^{-3} \mathrm{~m}$ & Estimate [16] \\
$\Delta g$ & $0.9 \times 10^{-3} \mathrm{~m}$ & $0.05 \times 10^{-3} \mathrm{~m}$ & Estimate \\
\hline
\end{tabular}

TABLE 5: Uncertainty budget for determination of time weighted average concentration of $\mathrm{Cu}^{2+}$ in water using a DGT passive sampler.

\begin{tabular}{|c|c|c|c|c|c|c|}
\hline Symbol & Source of uncertainty & Type & Standard uncertainty $u\left(x_{i}\right)$ & Distribution & Divisor & $U_{i}(\mathrm{M}) \mu \mathrm{g} \mathrm{L}^{-1}$ \\
\hline$M_{\mathrm{acc}}$ & Determination of accumulated mass & $\mathrm{A}$ & $6.14 \times 10^{-8} \mathrm{~g}$ & Normal & 1 & 0.49 \\
\hline$M_{\text {blank }}$ & Determination of contamination & A & $2.55 \times 10^{-9} \mathrm{~g}$ & Normal & 1 & 0.02 \\
\hline$D^{W}$ & Diffusion coefficient in water & A & $4.73 \times 10^{-11} \mathrm{~m}^{2} / \mathrm{s}$ & Normal & 1 & 0.16 \\
\hline$\Delta g$ & Thickness of material diffusion layer (MDL) & B & $2.89 \times 10^{-5} \mathrm{~m}$ & Rectangular & $\sqrt{3}$ & 0.33 \\
\hline$D^{\mathrm{MDL}}$ & Diffusion coefficient in MDL & A & $1.03 \times 10^{-11} \mathrm{~m}^{2} / \mathrm{s}$ & Normal & 1 & 0.16 \\
\hline$\delta$ & Diffusion boundary layer & $\mathrm{B}$ & $2.89 \times 10^{-5} \mathrm{~m}$ & Rectangular & $\sqrt{3}$ & 0.29 \\
\hline$t$ & Time & $\mathrm{B}$ & $624 \mathrm{~s}$ & Rectangular & $\sqrt{3}$ & 0.01 \\
\hline$A_{e}$ & Effective area & A & $2.08 \times 10^{-5} \mathrm{~m}^{2}$ & normal & 1 & 0.69 \\
\hline $\mathrm{Uc}\left(c_{b}\right)$ & Combined standard uncertainty & & & Normal & & 0.98 \\
\hline $\mathrm{Uc}\left(c_{b}\right)$ & Expanded standard uncertainty & & & $\operatorname{Normal}(k=2)$ & & 1.95 \\
\hline
\end{tabular}

TABLE 6: Results from sensitivity analysis, showing the effect on total uncertainty of the passive sampler measurement from reductions in uncertainty of selected parameters.

\begin{tabular}{lcc}
\hline Parameter & Change in uncertainty & Result on total uncertainty \\
\hline Effective area, $A_{e}$ & $50 \%$ reduction & Reduction from $7.6 \%$ to $6.1 \%$ in overall relative uncertainty \\
Recovery factor, $r$ & $50 \%$ reduction & Reduction from $7.6 \%$ to $6.9 \%$ in overall relative uncertainty \\
Diffusion boundary layer, $\delta$ & From $0.05 \mathrm{~mm}$ to $0.014 \mathrm{~mm}$ & Reduction from $7.6 \%$ to $7.3 \%$ in overall relative uncertainty \\
Diffusion pathway thickness & standard uncertainty & Reduction from $7.6 \%$ to $7.3 \%$ in overall relative uncertainty \\
Diffusion pathway thickness & $50 \%$ reduction & Increase from $7.6 \%$ to $12.2 \%$ in overall relative uncertainty \\
\hline
\end{tabular}

diffusion round the edges and the shrinkage of the gel resulted in an uncertainty that largely affects the end result, as it accounts for nearly $50 \%$ of the total uncertainty (see Figure 4). Uncertainties from the estimation of $M_{\text {acc }}$ account for roughly $25 \%$ of the total uncertainty, with the most significant factor being the estimation of extraction recovery.

A sensitivity analysis shows that halving the uncertainty for the effective radius and shrinkage in the determination of $A_{e}$ would reduce the contribution of $A_{e}$ to the overall uncertainty to roughly $20 \%\left(1.32 \pm 0.08 \mu \mathrm{gl}^{-1}\right.$ or $6.0 \%$ relative overall uncertainty). Similarly, a reduction in the uncertainty in the recovery factor, $r$, by $50 \%$, would reduce the contribution from $M_{\text {acc }}$ to overall uncertainty from $25 \%$ to approximately $9 \%\left(1.32 \pm 0.09 \mu \mathrm{gl}^{-1}\right.$ or $6.8 \%$ relative overall uncertainty). On the other hand, an increase in the uncertainty for diffusion layer thickness from $0.05 \mathrm{~mm}$ to
$0.2 \mathrm{~mm}$ would result in $1.32 \pm 0.16 \mu \mathrm{gl}^{-1}$ or $12.2 \%$ relative overall uncertainty. This is a significant increase in overall uncertainty and illustrates the sensitivity of the method to inconsistencies in the gel-membrane layer interface. Furthermore, the effects of uncertainty changes in DBL and diffusive layer thickness are shown in Table 6.

The sensitivity analysis shows that overall method uncertainty can be significantly reduced by addressing the proper sources of uncertainties and also that deterioration in diffusion layer consistency can have significant negative effects on overall method uncertainty.

\section{Conclusion}

An uncertainty analysis was performed for passive sampling of a metal ion in water to highlight critical steps in the method 
and to identify key factors for potential improvement. In the analysis performed here the uncertainty of the effective cross-sectional diffusion area $A_{e}$ was identified as the main contributor to overall uncertainty. Uncertainties in analyte recovery and material diffusion ranked second and third, respectively. An improvement in the estimation of $A_{e}$ was found to be an important step toward achieving a reduction in uncertainty in passive sampling. Optimization of the extraction procedure will provide a further reduction in overall uncertainty.

\section{Conflict of Interests}

The authors declare that there is no conflict of interests regarding the publication of this paper.

\section{References}

[1] European Commission, 2000/60/EC, 2000.

[2] H. Zhang and W. Davison, "Direct in situ measurements of labile inorganic and organically bound metal species in synthetic solutions and natural waters using diffusive gradients in thin films," Analytical Chemistry, vol. 72, no. 18, pp. 4447$4457,2000$.

[3] L. B. Blom, G. M. Morrison, J. Kingston et al., "Performance of an in situ passive sampling system for metals in stormwater," Journal of Environmental Monitoring, vol. 4, no. 2, pp. 258-262, 2002.

[4] I. J. Allan, J. Knutsson, N. Guigues, G. A. Mills, A. Fouillac, and R. Greenwood, "Evaluation of the chemcatcher and DGT passive samplers for monitoring metals with highly fluctuating water concentrations," Journal of Environmental Monitoring, vol. 9, no. 7, pp. 672-681, 2007.

[5] H. Zhang and W. Davison, "Performance characteristics of diffusion gradients in thin films for the in situ measurement of trace metals in aqueous solution," Analytical Chemistry, vol. 67, no. 19, pp. 3391-3400, 1995.

[6] W. Davison and H. Zhang, "Progress in understanding the use of diffusive gradients in thin films (DGT) back to basics," Environmental Chemistry, vol. 9, no. 1, pp. 1-13, 2012.

[7] C. Miège, S. Schiavone, A. Dabrin et al., "An in situ intercomparison exercise on passive samplers for monitoring metals, polycyclic aromatic hydrocarbons and pesticides in surface waters," Trends in Analytical Chemistry, vol. 36, pp. 128-143, 2012.

[8] W. Davison and H. Zhang, "In situ speciation measurements of trace components in natural waters using thin-film gels," Nature, vol. 367, no. 6463, pp. 546-548, 1994.

[9] W. G. Brumbaugh, J. D. Petty, T. W. May, and J. N. Huckins, “A passive integrative sampler for mercury vapor in air and neutral mercury species in water," Chemosphere-Global Change Science, vol. 2, no. 1, pp. 1-9, 2000.

[10] J. K. Kingston, R. Greenwood, G. A. Mills, G. M. Morrison, and L. B. Persson, "Development of a novel passive sampling system for the time-averaged measurement of a range of organic pollutants in aquatic environments," Journal of Environmental Monitoring, vol. 2, no. 5, pp. 487-495, 2000.

[11] J. Rozemeijer, Y. van der Velde, H. de Jonge, F. van Geer, H. P. Broers, and M. Bierkens, "Application and evaluation of a new passive sampler for measuring average solute concentrations in a catchment scale water quality monitoring study," Environmental Science and Technology, vol. 44, no. 4, pp. 1353-1359, 2010.

[12] S. L. R. Ellison and A. Williams, "Eurachem/CITAC guide: Quantifying Uncertainty in Analytical Measurement," 2012.

[13] H. Zhang, W. Davison, R. Gadi, and T. Kobayashi, "In situ measurement of dissolved phosphorus in natural waters using DGT," Analytica Chimica Acta, vol. 370, no. 1, pp. 29-38, 1998.

[14] E. R. Unsworth, H. Zhang, and W. Davison, "Use of diffusive gradients in thin films to measure cadmium speciation in solutions with synthetic and natural ligands: comparison with model predictions," Environmental Science and Technology, vol. 39, no. 2, pp. 624-630, 2005.

[15] S. Scally, W. Davison, and H. Zhang, "Diffusion coefficients of metals and metal complexes in hydrogels used in diffusive gradients in thin films," Analytica Chimica Acta, vol. 558, no. 1-2, pp. 222-229, 2006.

[16] K. W. Warnken, H. Zhang, and W. Davison, "Accuracy of the diffusive gradients in thin-films technique: diffusive boundary layer and effective sampling area considerations," Analytical Chemistry, vol. 78, no. 11, pp. 3780-3787, 2006.

[17] I. J. Allan, J. Knutsson, N. Guigues, G. A. Mills, A. Fouillac, and R. Greenwood, "Chemcatcher and DGT passive sampling devices for regulatory monitoring of trace metals in surface water," Journal of Environmental Monitoring, vol. 10, no. 7, pp. 821-829, 2008.

[18] S. Nelms, Inductively Coupled Plasma Mass Spectrometry Handbook, Blackwell, 2005.

[19] V. J. Barwick, S. L. R. Ellison, and B. Fairman, "Estimation of uncertainties in ICP-MS analysis: a practical methodology," Analytica Chimica Acta, vol. 394, no. 2-3, pp. 281-291, 1999.

[20] J. R. Taylor, An Introduction to Error Analysis, University Science books, Sausalito, Calif, USA, 1997.

[21] J. Kragten, "Tutorial review. Calculating standard deviations and confidence intervals with a universally applicable spreadsheet technique," The Analyst, vol. 119, no. 10, pp. 2161-2165, 1994.

[22] P. Evans and B. Fairman, "High resolution ID-ICP-MS certification of an estuary water reference material (LGC 6016) and analysis of matrix induced polyatomic interferences," Journal of Environmental Monitoring, vol. 3, no. 5, pp. 469-474, 2001.

[23] H. Zhang and W. Davison, "Diffusional characteristics of hydrogels used in DGT and DET techniques," Analytica Chimica Acta, vol. 398, no. 2-3, pp. 329-340, 1999. 

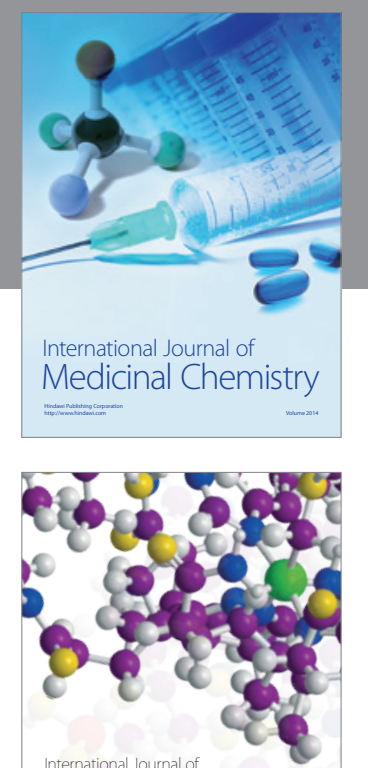

\section{Carbohydrate} Chemistry

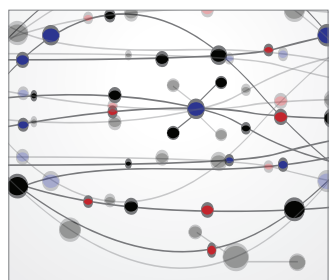

The Scientific World Journal
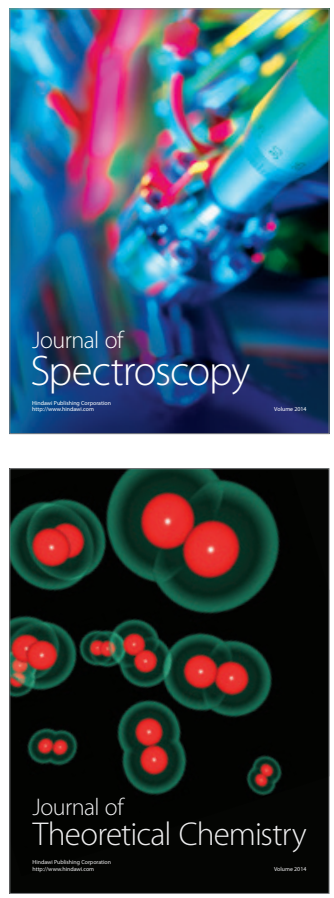
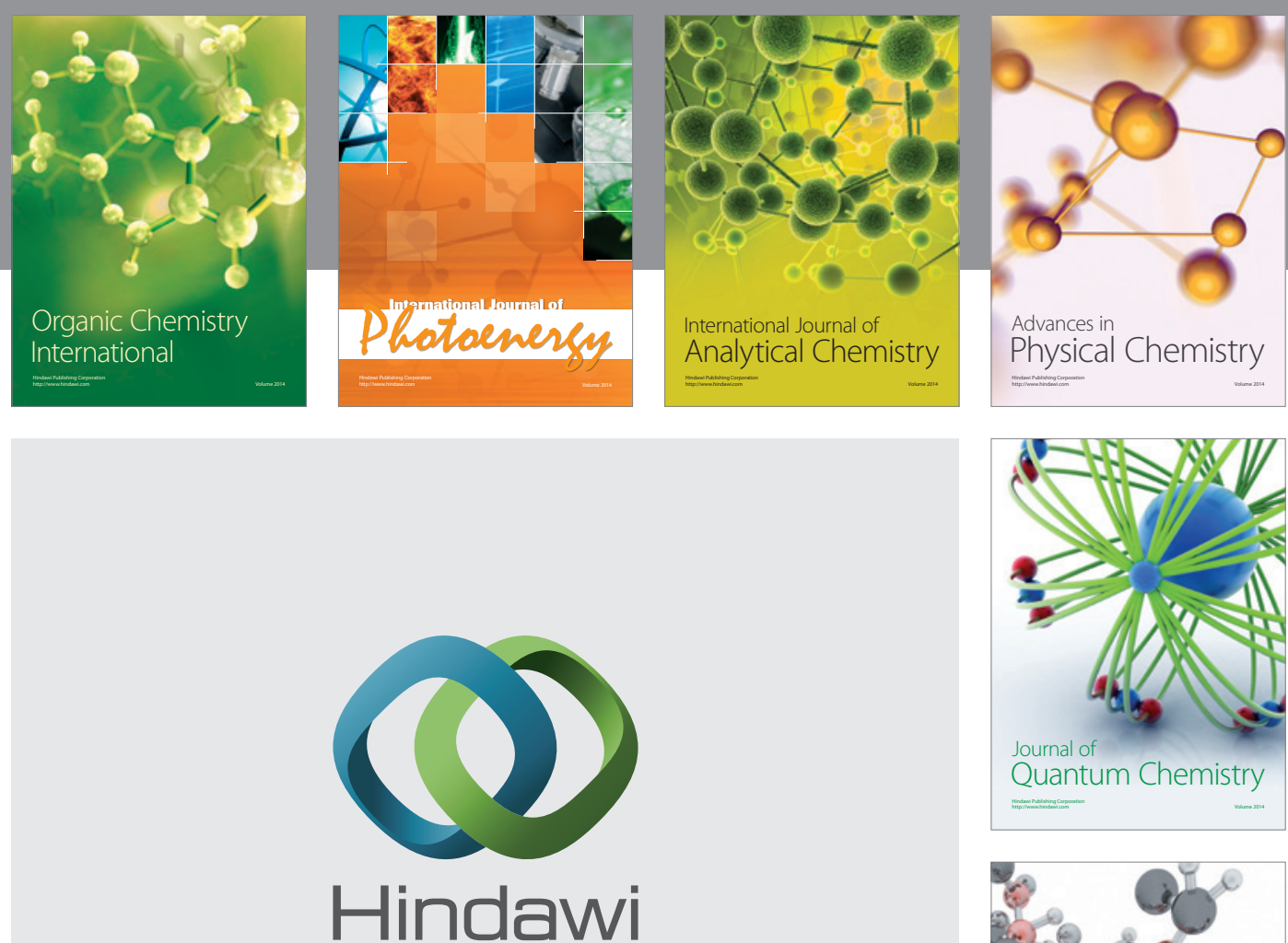

Submit your manuscripts at

http://www.hindawi.com

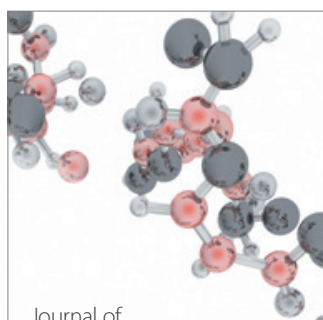

Analytical Methods

in Chemistry

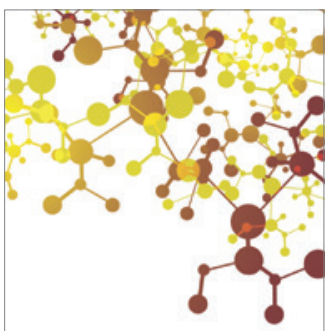

Journal of

Applied Chemistry

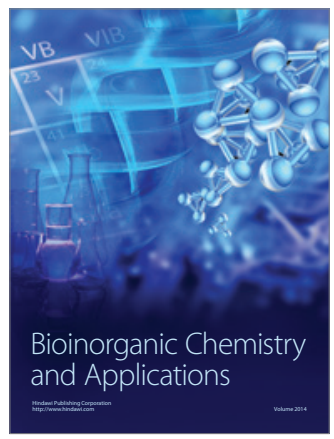

Inorganic Chemistry
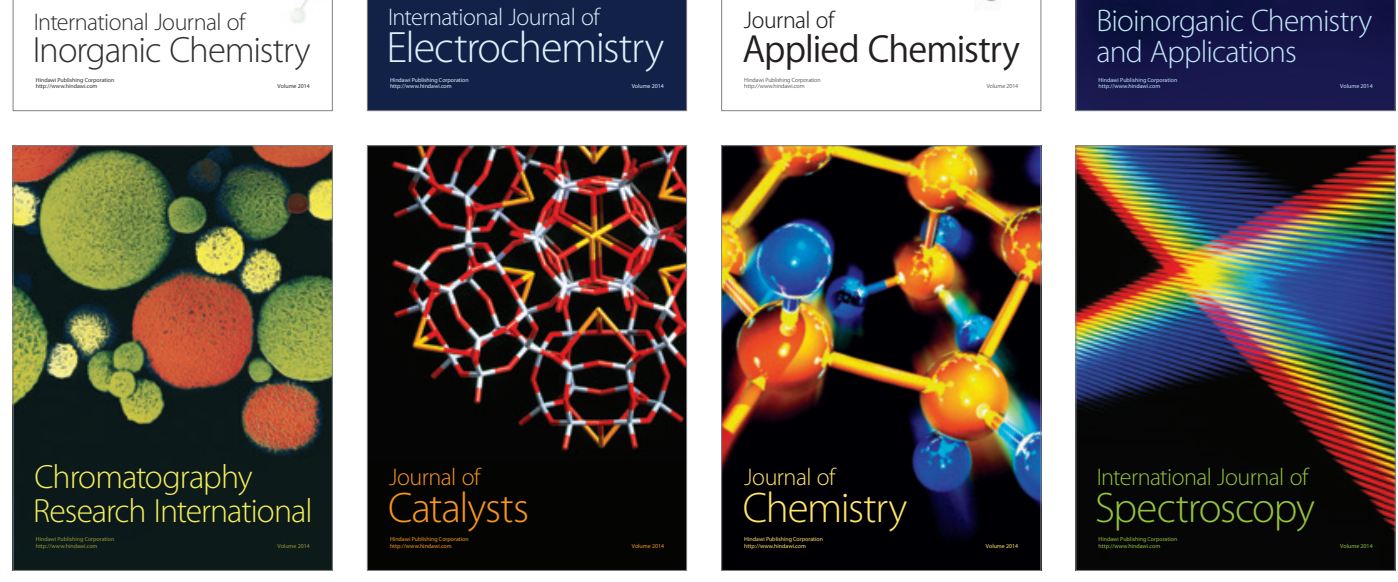